\title{
Effects of epigallocatechin gallate on regulatory $T$ cell number and function in obese $v$. lean volunteers
}

\author{
Jung-Mi Yun, Ishwarlal Jialal and Sridevi Devaraj* \\ Department of Pathology and Laboratory Medicine, University of California, Davis, Medical Center, Sacramento, CA, USA
}

(Received 12 August 2009 - Revised 9 November 2009 - Accepted 17 December 2009 - First published online 23 February 2010)

Obesity predisposes to an increased incidence of diabetes and CVD. Also, obesity is a pro-inflammatory state. Regulatory T cells (Tregs) are essential negative regulators of inflammation and are down-regulated in pro-inflammatory states. Animal models of obesity are associated with decreased Tregs. The dietary modulation of Tregs could be used as a therapeutic strategy to control inflammation. Epigallocatechin gallate (EGCG) is a potent anti-inflammatory agent and an active ingredient of green tea and is suggested to have a role as a preventive agent in obesity, diabetes and CVD. The role of EGCG in the modulation of Tregs has, however, not been studied. Thus, the aim of the present study was to determine the effect of EGCG on the number and function of Tregs in obese and lean human subjects in vitro, and to delineate its specific regulation mechanisms. Tregs were isolated from normal-weight and obese subjects. Tregs were cultured in the absence or presence of EGCG $(20 \mu \mathrm{M})$ for $24 \mathrm{~h}$. Foxp3-expressing Tregs were enumerated using flow cytometry. Histone deacetylase (HDAC) activity and nuclear NF- $\mathrm{kBp} 65$ level were measured by ELISA and Western blots. Obese subjects had lower Tregs and IL-10 production than lean subjects. EGCG treatment significantly enhanced the number of Foxp3-expressing Tregs and IL-10 production in vitro $(P<0 \cdot 05)$ in both groups. Also, EGCG decreased NF- $\mathrm{KB}$ activity and increased HDAC activity and HDAC-2 expression in Tregs $(P<0.05)$ in both groups. Thus, in part, EGCG enhances the functionality of Tregs, i.e. IL-10 production and number by suppressing the NF- $\kappa \mathrm{B}$ signalling pathway via inducing epigenetic changes.

Regulatory T cells: Inflammation: Green tea: Epigenetics

Obesity is increasingly recognised as a public health burden, because it is associated with an increased risk for many diseases, including the metabolic syndrome, i.e. hypertension, insulin resistance or type 2 diabetes mellitus, arteriosclerosis and $\mathrm{CHD}^{(1)}$. Obesity is associated with increased inflammation, as evidenced by increased levels of C-reactive protein, and decreased anti-inflammatory cytokines, such as IL-10 ${ }^{(2)}$. Obese individuals exhibit impaired immune responses. Immune and autoimmune responses are controlled by a fine balance between effector $\mathrm{T}$ cells (Teffs) and regulatory $\mathrm{T}$ cells (Tregs). Tregs are essential negative regulators of immune responses. $\mathrm{CD} 4{ }^{+} \mathrm{CD} 25^{+}$Treg lymphocytes produce IL-10 and transforming growth factor- $\beta$; these are important in controlling inflammatory $\mathrm{T}$ cells (both $\mathrm{Th} 1$ and $\mathrm{Th} 2)^{(3)}$. It is now evident that Tregs are important in immunity and inflammation. Sakaguchi demonstrated that depletion of $\mathrm{CD} 4{ }^{+} \mathrm{CD} 25^{+}$Tregs results in systemic autoimmune disease in mice ${ }^{(4)}$. $\mathrm{CD} 4^{+} \mathrm{CD} 25^{+}$Tregs with a reduced in vitro suppressive function were found in some studies performed on patients with type 1 diabetes mellitus and atherosclerosis, especially those with acute coronary syndromes ${ }^{(5-7)}$. Furthermore, recent studies have demonstrated that the forkhead family transcription factor (Foxp3) is predominantly expressed in $\mathrm{CD} 4{ }^{+} \mathrm{CD} 25^{+}$Tregs and plays a critical role for their development and function. Mutations in the transcription factor Foxp3 are associated with severe autoimmune diseases in man and the mouse ${ }^{(8-10)}$. Thus, enhancement of $\mathrm{CD} 4^{+} \mathrm{CD} 25^{+}$Foxp $^{-}$Treg cell activity may be important in controlling immunity and inflammation.

Histone acetylation-deacetylation is an important epigenetic event that plays an important role in inflammation ${ }^{(11)}$. Acetylation by histone acetyltransferases of specific lysine residues on the $\mathrm{N}$-terminal tail of core histones results in uncoiling of the DNA and increased accessibility to transcription factor binding. In contrast, histone deacetylation by histone deacetylases (HDAC) represses gene transcription by promoting DNA winding, thereby limiting access to transcription factors. Furthermore, inhibiting HDAC resulted in enhanced activation of NF- $\mathrm{B}^{(12)}$ and increased histone acetylation, culminating in increased pro-inflammatory cytokines. HDAC-2 has been reported to function in a corticosteroidmediated anti-inflammatory mechanism ${ }^{(13)}$. HDAC-1 and -2 can interact directly with the p65 subunit of NF- $\mathrm{BB}$ to exert its co-repressor function in the nucleus ${ }^{(14)}$. There is increasing evidence to suggest that HDAC plays an important role in regulating the pro-inflammatory response.

(-)-Epigallocatechin gallate (EGCG) is one of the major green tea catechins that are suggested to have a role as a

Abbreviations: APC, allophycocyanin; EGCG, epigallocatechin gallate; Foxp3, forkhead family transcription factor; HDAC, histone deacetylases; PE, phycoerythrin; Tregs, regulatory $\mathrm{T}$ cells.

* Corresponding author: Dr Sridevi Devaraj, fax +19167346593, email sridevi.devaraj@ucdmc.ucdavis.edu 
preventive agent in cancer, obesity, diabetes and $\mathrm{CVD}^{(15)}$. Due to the dominant role of CVD and the dramatic rise of obesity and type 2 diabetes mellitus as major and interlinked healthcare problems, green tea and EGCG are increasingly being investigated in these areas ${ }^{(15)}$. Additionally, there are numerous in vivo studies demonstrating that EGCG exert cardiovascular and metabolic benefits in these model systems. Therefore, EGCG, a food component, can be regarded as useful for the maintenance of cardiovascular and metabolic health $^{(15)}$. However, there is a paucity of data examining the modulation of the number and function of Tregs with nutritional supplements.

The antioxidant and/or anti-inflammatory effects of dietary polyphenols (curcumin and resveratrol) have all been shown to play a role in either controlling NF- $\kappa \mathrm{B}$ activation or chromatin remodelling through the modulation of HDAC activity and subsequently inflammatory gene expression ${ }^{(15-16)}$. However, there is a paucity of data on EGCG and HDAC activity in relation to inflammation and the function of Tregs. Also, there is a paucity of data on Tregs in obesity. Obesity is associated with increased inflammation and decreased anti-inflammatory cytokines, such as IL-10 ${ }^{(2)}$. Thus, we hypothesise that EGCG enhances the functionality and number of Tregs through suppressing the NF- $\mathrm{BB}$ signalling pathway via inducing epigenetic changes, i.e. enhanced HDAC activity in obese human subjects.

\section{Experimental methods}

\section{Materials}

Anti-HDAC-2 and anti-HDAC-3 were procured from Active Motif (Carlsbad, CA, USA) and anti-NF-кBp65 antibodies were procured from Cell Signaling Technology (Beverly, MA, USA). A CD4 ${ }^{+} \mathrm{CD} 25^{+}$Regulatory $\mathrm{T}$ Cell Isolation kit was procured from Miltenyi Biotec (Auburn, CA, USA). CD25-allophycocyanin (APC)-Cy7, CD4-phycoerythrin (PE)Cy7 and Foxp3-Alexa Fluor antibodies were purchased from BD Biosciences (San Jose, CA, USA). A transcription ELISA kit (TransAM NF-кBp65) and HDAC assay kit (colorimetric) were purchased from Active Motif. A Human IL-10 Quantikine HS ELISA kit was purchased from R\&D Systems (Minneapolis, MN, USA). All other chemicals, unless otherwise stated, were obtained from Sigma (St Louis, MO, USA). The present study was conducted according to the guidelines laid down in the Declaration of Helsinki and all procedures involving human subjects were approved by the University of California Davis Institutional Review Board. Written informed consent was obtained from all subjects.

\section{Subject selection and regulatory $T$ cell isolation}

Fasting blood $(40 \mathrm{ml})$ was obtained from normal-weight healthy donors $\left(\mathrm{BMI}<25 \mathrm{~kg} / \mathrm{m}^{2}\right)$ and obese donors $\left(\mathrm{BMI}>30 \mathrm{~kg} / \mathrm{m}^{2}\right)$ (twelve donors per group). Blood was obtained in heparinised vacutainers and all complete blood cell counts were normal. Twelve lean and twelve obese donors were age-, sex- and race-matched and recruited. Lean and obese subjects were recruited according to the selection criteria (Table 1).
Table 1. Selection criteria of the study subjects

\begin{tabular}{|c|c|c|}
\hline Criteria & Non-obese subjects & Obese subjects \\
\hline \multicolumn{3}{|l|}{ Inclusion } \\
\hline Age range (years) & $18-70$ & $18-70$ \\
\hline \multicolumn{3}{|l|}{ Waist (inches) ${ }^{\star}$} \\
\hline Male subjects & $<40$ & $>40$ \\
\hline Female subjects & $<35$ & $>35$ \\
\hline BMI $\left(\mathrm{kg} / \mathrm{m}^{2}\right)$ & $<25$ & $>30$ \\
\hline Fasting glucose (mg/l) & $<1260 \mathrm{mg} / \mathrm{l}$ & $<1260 \mathrm{mg} / \mathrm{l}$ \\
\hline \multicolumn{3}{|l|}{ Exclusion (all subjects) } \\
\hline Abnormal liver function & \multicolumn{2}{|c|}{$\begin{array}{l}\text { AST and/or ALT greater than two times } \\
\text { upper limit of normal }\end{array}$} \\
\hline Abnormal kidney function & \multicolumn{2}{|c|}{ Creatinine $>15 \mathrm{mg} / \mathrm{l}$} \\
\hline Total cholesterol (mg/l) & \multicolumn{2}{|l|}{$>2500$} \\
\hline TAG (mg/l) & \multicolumn{2}{|l|}{$>4000$} \\
\hline C-reactive protein (mg/l) & \multicolumn{2}{|l|}{$>10$} \\
\hline Anti-inflammatory drugs & \multicolumn{2}{|c|}{$\begin{array}{l}\text { Use of anti-inflammatory drugs except } \\
\text { aspirin } 81 \mathrm{mg} / \mathrm{d}\end{array}$} \\
\hline Supplements & \multicolumn{2}{|c|}{$\begin{array}{l}\text { Use of multivitamin/antioxidant } \\
\text { supplements (vitamin } C>500 \mathrm{mg} / \mathrm{d} \\
\text { and vitamin } E \geq 200 \mathrm{IU} / \mathrm{d}+\text { ) or fish oil } \\
\text { supplementation }(1 \mathrm{~g} / \mathrm{d}) \text { in the past } \\
6 \text { months }\end{array}$} \\
\hline Alcohol & \multicolumn{2}{|c|}{$\begin{array}{l}\text { Consumption of }>1 \mathrm{oz} / \mathrm{d} \text { in the past } \\
3 \text { months } \ddagger\end{array}$} \\
\hline Pregnancy or lactation & & \\
\hline Blood pressure & \multicolumn{2}{|c|}{$\begin{array}{l}\text { Systolic blood pressure }>150 \text { or dias- } \\
\text { tolic blood pressure }>100 \mathrm{mmHg}\end{array}$} \\
\hline Smoking & & \\
\hline
\end{tabular}

AST, aspartate transaminase; ALT, alanine transaminase.

* 1 inch $=2.54 \mathrm{~cm}$.

†200 IU vitamin $E=133.33 \mathrm{mg} \mathrm{d}-\alpha$-tocopherol.

$\ddagger 1 \mathrm{oz}=28.35 \mathrm{~g}$.

Peripheral blood mononuclear cells from lean and obese subjects were isolated by Ficoll-Hypaque gradient (Sigma) ${ }^{(17)}$ and then $\mathrm{CD} 4{ }^{+} \mathrm{CD} 25^{+}$Tregs were purified from isolated peripheral blood mononuclear cells using a $\mathrm{CD} 4{ }^{+} \mathrm{CD} 25^{+}$Regulatory $\mathrm{T}$ Cell Isolation kit according to the manufacturer's protocols (Miltenyi Biotec). Briefly, $\mathrm{CD} 4^{+} \mathrm{T}$ cells were negatively selected from the total peripheral blood mononuclear cells, yielding a population of $\mathrm{CD}^{+}$ cells with purity of $92-98 \%$. Positive selection on antiCD25 magnetic microbeads was then used to separate the negative fraction containing $\mathrm{CD} 4{ }^{+} \mathrm{CD} 25^{-} \mathrm{T}$ cells from the $\mathrm{CD} 4{ }^{+} \mathrm{CD} 25^{+} \mathrm{T}$ cell fraction, using the $\mathrm{CD} 4{ }^{+} \mathrm{CD} 25^{+}$ Regulatory $\mathrm{T}$ Cell Isolation kit from Miltenyi Biotec. The purities of the sorted $\mathrm{CD} 4{ }^{+} \mathrm{CD} 25^{+}$populations were always $>95 \%$ as confirmed by flow cytometry. Cells were then applied to a second magnetic column, washed, and eluted again. Tregs were stained using three different antibodies such as CD4-PE-Cy7, CD25-APC-Cy7 and Foxp3-Alexa Fluor with a different colour using flow cytometry. CD4 and CD25 antibodies were used for the surface staining of the Tregs. The Foxp3 antibody was used for the intracellular staining of the Tregs.

\section{Regulatory $T$ cell staining in whole blood}

Tregs were stained using two different antibodies, i.e. CD4-PE-Cy7 and CD25-APC-Cy7, in whole blood by flow cytometry. CD4 and CD25 were used for the surface staining 
of the Tregs. To $100 \mu l$ of whole blood from both groups, $10 \mu \mathrm{l}$ of Fcy blocking reagent were added. Blood samples were incubated with $10 \mu \mathrm{l}$ isotype control and/or $10 \mu \mathrm{l}$ appropriate antibodies (CD25-APC-Cy7 and CD4-PE-Cy7) for $30 \mathrm{~min}$ at $4^{\circ} \mathrm{C}$ in the dark. After incubation, lysis buffer was added to the whole blood. Cells were centrifuged and washed with PBS and re-suspended in $1 \%$ paraformaldehyde (PFA) buffer. At least 10000 cells were acquisitioned using flow cytometry (BD Biosciences).

\section{Cell culture and treatment with epigallocatechin gallate}

Tregs were isolated from normal-weight and obese subjects. Tregs were cultured in Roswell Park Memorial Institute (RPMI) medium containing $10 \%$ heat-inactivated fetal calf serum, $1 \%$ antibiotics and IL-2 $(10 \mathrm{ng} / \mathrm{ml})$ for the maintenance of Tregs at $37^{\circ} \mathrm{C}$ and $5 \% \mathrm{CO}_{2}$. EGCG (dissolved in RPMI medium) was used for the treatment of cells. Tregs (50-60\% confluent) were cultured in the absence or presence of EGCG $(20 \mu \mathrm{M})$ for $24 \mathrm{~h}$. After $24 \mathrm{~h}$ incubation, the medium was saved for the measurement of IL-10 and cells were washed with PBS and then harvested for further studies.

\section{Surface and intracellular staining of regulatory $T$ cells}

Tregs were stained using three different antibodies such as CD4-PE-Cy7, CD25-APC-Cy7 and Foxp3-Alexa Fluor by flow cytometry. For Foxp3 intracellular staining, cells were incubated with CD25-APC-Cy7 and CD4-PE-Cy7 antibodies at first for $30 \mathrm{~min}$ at $4^{\circ} \mathrm{C}$ in the dark. After incubation, these cells were washed and then fixed and stained with the Foxp3-Alexa Fluor antibody according to the manufacturer's instructions (BD Biosciences). Cells were washed three times and re-suspended in $1 \%$ PFA buffer. At least 10000 cells were assayed by flow cytometry (BD Biosciences).

\section{Measurement of IL-10 production in regulatory $T$ cells}

After treatment of cells with EGCG and without EGCG for $24 \mathrm{~h}$, the supernatant fraction was saved and stored at $-80^{\circ} \mathrm{C}$. IL- 10 levels were assayed in the supernatant fraction of treated cells using the Human IL-10 Quantikine HS ELISA kit according to the manufacturer's protocols (R\&D Systems).

\section{Preparation of nuclear lysates}

After treatment of cells with and without EGCG, the cells were washed twice in PBS (10 mM; pH 7.4). Nuclear lysates were prepared using NE-PER Nuclear and Cytoplasmic Extraction Reagents (Pierce, Thermo Scientific, Rockford, IL, USA). The lysates were collected and cleared by centrifugation and the supernatant fraction sampled and stored at $-80^{\circ} \mathrm{C}$. The protein concentration in the lysates was measured by BCA protein assay (Pierce) according to the manufacturer's protocols.

\section{Western blot analysis}

For Western blot analysis, $12 \mu \mathrm{g}$ protein was resolved over $\quad 4-20 \%$ 2-amino-2-(hydroxymethyl)propane-1,3-diol (Tris)-glycine polyacrylamide gels (Invitrogen, Carlsbad, CA, USA), transferred onto nitrocellulose membranes, and subsequently incubated in blocking buffer $(5 \%$ non-fat dry milk/1\% Tween 20; in $20 \mathrm{~mm}$-Tris-buffered saline ( $\mathrm{pH} 7 \cdot 6)$ ) for $2 \mathrm{~h}$. The blots were incubated with appropriate primary antibodies (HDAC-2 and NF-кBp65, 1:1000 dilution), washed, and incubated with the appropriate secondary horseradish peroxidase-conjugated antibody (1:2000 dilution). The blots were detected with chemiluminescence (ECL kit; Amersham Biosciences, Piscataway, NJ, USA) and autoradiography, using XAR-5 film (Eastman Kodak, Rochester, NY, USA). Equal loading of protein was confirmed by stripping the blots and reprobing with lamin (Sigma).

\section{Measurement of histone deacetylase activity using ELISA}

Following treatment of cells with and without $20 \mu \mathrm{M}$-EGCG for $24 \mathrm{~h}$, cells were harvested and nuclear lysates were prepared. A quantity of $10 \mu \mathrm{g}$ nuclear lysate protein from each group was taken for determination of HDAC activity. The experiment was done according to the manufacturer's instructions (HDAC assay kit; Active Motif). Absorbance was taken at $405 \mathrm{~nm}$ by using an ELISA reader (Multiscan MCC/340; Fisher Scientific, Rockford, IL, USA).

\section{Detection of transcription factor NF-кBp65 using ELISA}

The commercially available kit for NF-кBp65 (Active Motif) contains the specific oligos with the specific consensus sequence for NF-кBp65 binding. Nuclear lysate protein $(5 \mathrm{mg})$ from each group was taken for quantification of NF- $\mathrm{KB}$ activity. The experiment was done according to the manufacturer's instructions. Absorbance was taken at $450 \mathrm{~nm}$ by using the ELISA reader (Multiscan MCC/340; Fisher Scientific).

\section{Immunocytochemical staining of histone deacetylase}

After $24 \mathrm{~h}$ incubation in the absence or presence of EGCG, cells $\left(1 \times 10^{4}\right)$ were placed on slides, the slides were air dried, fixed with $4 \%$ formaldehyde for $30 \mathrm{~min}$ at $4^{\circ} \mathrm{C}$, and then stained with HDAC-2 and -3 antibodies (1:1000) for $18 \mathrm{~h}$ at $4^{\circ} \mathrm{C}$. Slides were washed first in PBS (pH 7.2) with Tween 20 and then in PBS (10 min each). After being air dried, slides were incubated with the appropriate secondary antibody (1:2000) for $60 \mathrm{~min}$. The slides were washed as described above, air dried, mounted with mounting medium, and then examined with a fluorescence microscope at $\times 400$ magnification.

\section{Statistical analysis}

All in vitro experiments were conducted at least five times in duplicate. Results were expressed as mean values and standard deviations. Statistical analysis was performed 

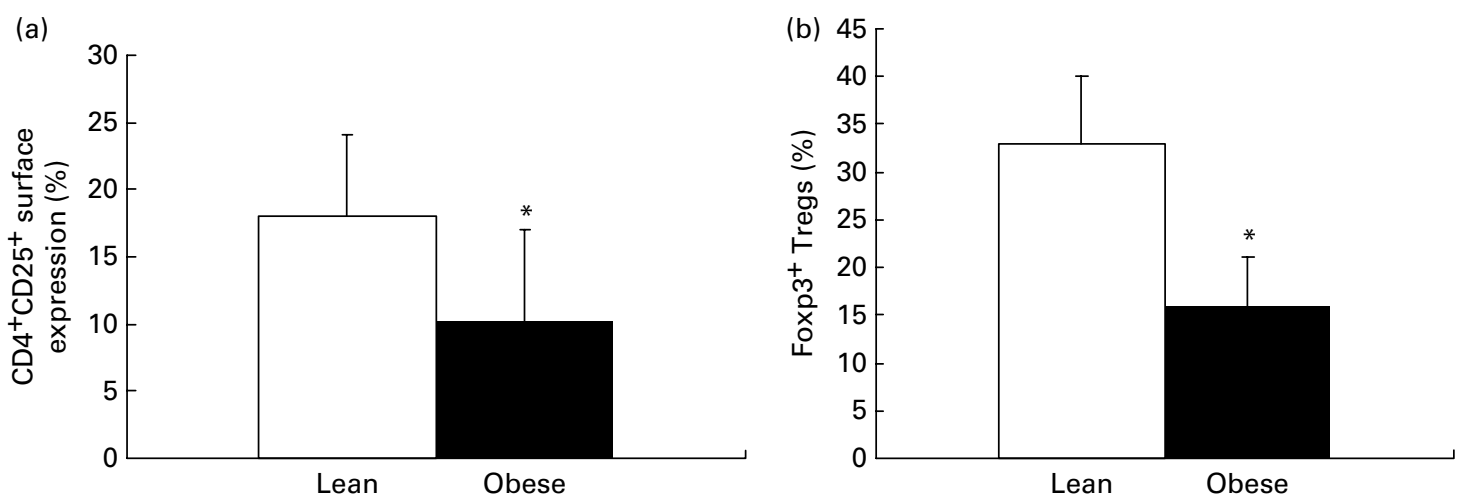

Fig. 1. Decreased number of regulatory $T$ cells (Tregs) in obese compared with normal-weight human subjects. (a) Tregs were stained using two different antibodies (CD4-phycoerythrin (PE)-Cy7 and CD25-allophycocyanin (APC)-Cy7) in whole blood by flow cytometry. (b) Tregs were isolated from fasting blood obtained from normal-weight and obese subjects as described in Experimental methods. Tregs of obese and lean subjects were stained with three different antibodies (CD25-APC-Cy7, CD4-PE-Cy7 and forkhead family transcription factor (Foxp3)-Alexa Fluor) by flow cytometry. Results are mean values (for twelve subjects per group), with standard deviations represented by vertical bars. * Mean value was significantly different from that of the normal-weight subjects $(P<0.05)$.

using ANOVA followed by Wilcoxon tests. $P<0.05$ was considered significant.

\section{Results}

Foxp3-positive regulatory $T$ cell numbers are decreased in obese compared with lean human subjects

As shown in Fig. 1(a), the $\mathrm{CD} 4{ }^{+} \mathrm{CD} 25^{+}$Tregs in whole blood were 10.2 (SD 6.78) and 17.25 (SD 6.15) \% in obese and lean subject groups, respectively (Fig. 1(a)). Thus, $\mathrm{CD} 4{ }^{+} \mathrm{CD} 25^{+}$ Tregs were significantly decreased in obese subjects compared with lean subjects $(P<0.05)$ (Fig. 1(a)). We then evaluated the expression of Foxp 3 in $\mathrm{CD} 4{ }^{+} \mathrm{CD} 25^{+}$Tregs in obese $v$. lean subjects using flow cytometry. The purity of positively selected $\mathrm{CD} 4{ }^{+} \mathrm{CD} 25^{+}$Tregs was $>96 \%$ as confirmed by flow cytometry in both groups. At least 10000 cells were assayed using flow cytometry (BD Bioscience). Half of the purified $\mathrm{CD}^{+} \mathrm{CD} 25^{+}$Tregs were Foxp3-positive. Foxp3expressing $\mathrm{CD} 4{ }^{+} \mathrm{CD} 25^{+}$Tregs were significantly decreased in obese subjects compared with lean subjects $(P<0.05)$ (Fig. 1(b)).

In vitro treatment with epigallocatechin gallate significantly induced Foxp $3^{+}$-expressing regulatory $T$ cells among the $C D 4^{+} C D 25^{+}$population and IL-10 secretion in obese and lean subjects

The role of EGCG in the modulation of Tregs has, however, not been studied. Thus, we studied the effect of EGCG on the number and function of Tregs in vitro. Thus, we selected this dose in further experiments. As shown in Fig. 2, Foxp $3^{+}$ expressing cells among the $\mathrm{CD} 4{ }^{+} \mathrm{CD} 25^{+}$population were significantly increased after EGCG treatment $(20 \mu \mathrm{M})$ in vitro in both groups (lean: untreated 50.4 (SD 1.2) \%, treated 58.8 (SD 2) \%; obese: untreated 54.2 (SD 3) \%, treated 55.9 (SD 0.5) $\%)$. IL-10 production was also significantly up-regulated by EGCG $(20 \mu \mathrm{M})$ treatment $(n 5$; Fig. $2 ; P<0 \cdot 01)$ in both groups (lean: untreated 2.37 (SD 0.21) pg/mg, treated 5.14 (SD 0.25) $\mathrm{pg} / \mathrm{mg}$; obese: untreated 2.68 (SD 0.08$) \mathrm{pg} / \mathrm{mg}$, treated 4.53 (SD $0.03) \mathrm{pg} / \mathrm{mg}$ ). There was a similar increase in Foxp3 $3^{+}$Tregs and increase in IL-10 in the lean and obese subjects following
EGCG treatment. Dose-response studies with EGCG $(0 \cdot 5-20 \mu \mathrm{M})$ demonstrated that EGCG $(20 \mu \mathrm{M})$ was the most effective concentration that consistently up-regulated the number of Tregs and IL-10 production (Supplemental Fig. 1).
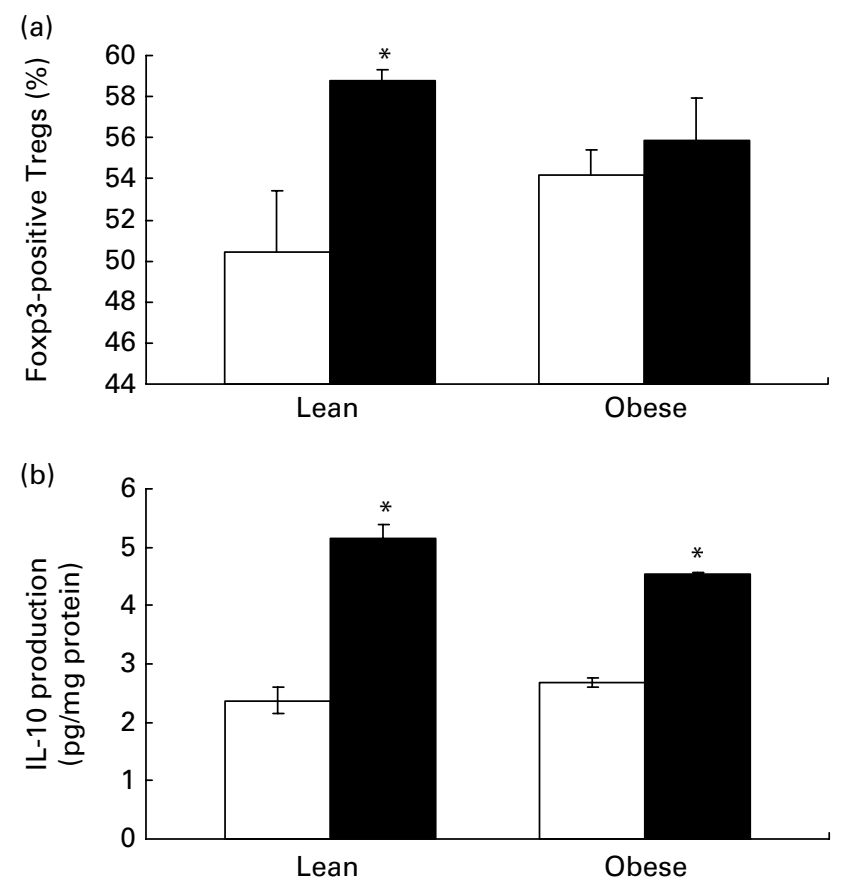

Fig. 2. (a) Epigallocatechin gallate (EGCG) treatment significantly induced forkhead family transcription factor (Foxp3)-positive regulatory $T$ cells (Tregs) among the $\mathrm{CD} 4{ }^{+} \mathrm{CD} 25^{+}$Treg population in obese and lean subject groups. Tregs were isolated from fasting blood obtained from obese and lean human subjects as described in Experimental methods. Tregs were cultured in Roswell Park Memorial Institute (RPMI) medium. The cells (50-60\% confluent) were treated with $(\square)$ and without $(\square) 20 \mu \mathrm{M}-\mathrm{EGCG}$ for $24 \mathrm{~h}$. The cells were analysed for the expression of $\mathrm{CD} 4^{+}, \mathrm{CD} 25^{+}$and Foxp3 ${ }^{+}$by flow cytometry. (b) EGCG treatment ( $\mathbf{\square})$ induces anti-inflammatory cytokine IL-10 in the Tregs of obese and lean subjects. IL-10 levels were detected in supernatant fractions using a Human IL-10 Quantikine HS ELISA kit and normalised to mg protein. ( $\square$ ), Untreated cells. Results are mean values (for five different experiments), with standard deviations represented by vertical bars. * Mean value was significantly different from that of the untreated Tregs $(P<0.05)$. 
(a)

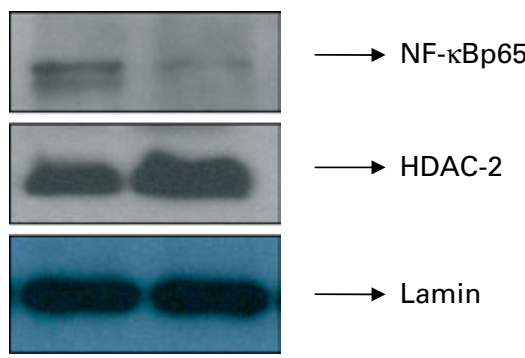

Untreated $20 \mu \mathrm{M}-\mathrm{EGCG}$

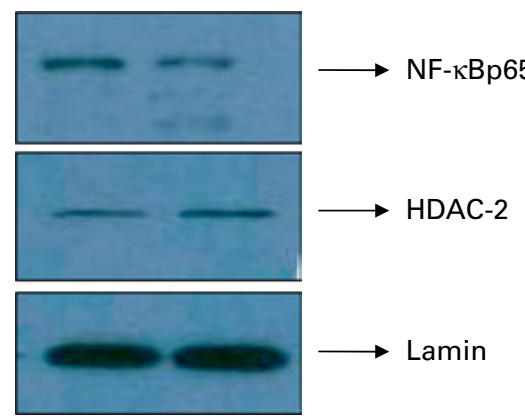

Untreated $20 \mu \mathrm{M}-\mathrm{EGCG}$

(d)
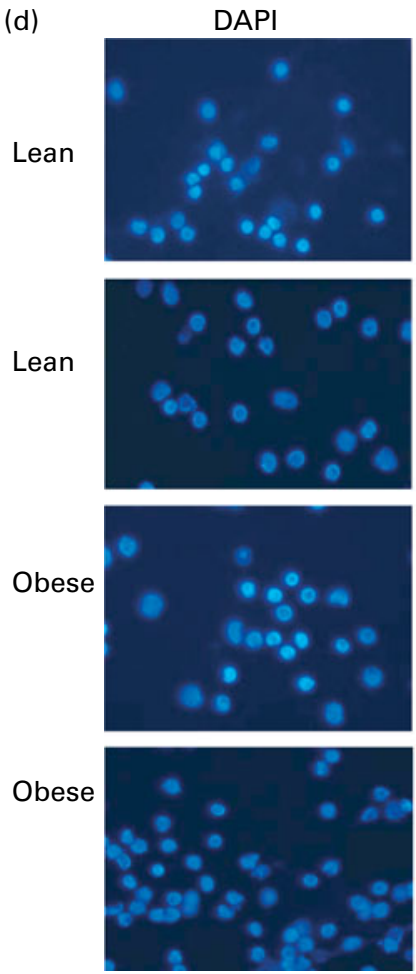

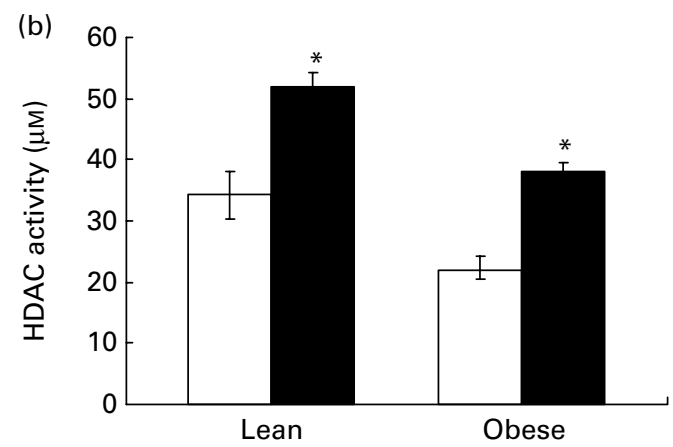

(c)
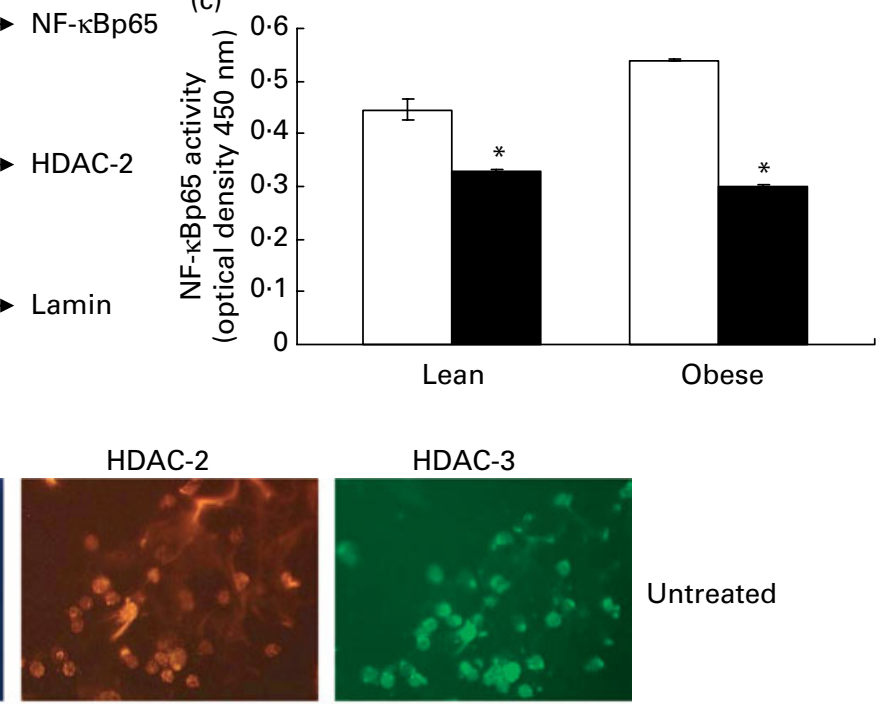

Untreated
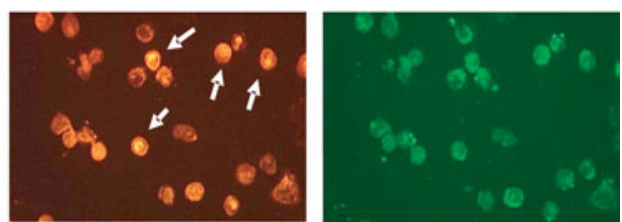

$20 \mu \mathrm{M}-\mathrm{EGCG}$
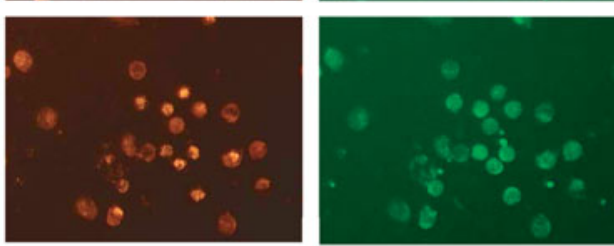

Untreated
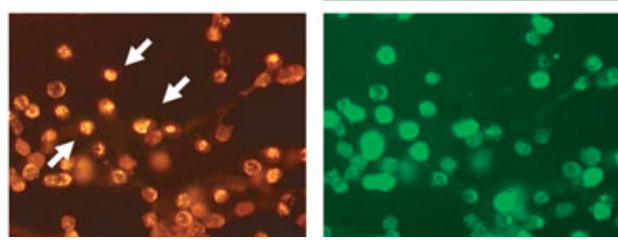

$20 \mu \mathrm{M}-\mathrm{EGCG}$

Fig. 3. (a-c). Epigallocatechin gallate (EGCG) treatment modulated NF-кBp65 and histone deacetylase (HDAC) levels in regulatory T cells (Tregs). The cells (50-60\% confluent) were treated with $(\square)$ and without $(\square) 20 \mu \mathrm{M}-E G C G$ for $24 \mathrm{~h}$. Cells were harvested and nuclear lysates were prepared. (a) For the Western blot analysis, protein was subjected to SDS-PAGE and used HDAC-2 and NF-кBp65 antibodies (1:1000 dilution) as detailed in the Experimental methods section. Equal loading of protein was confirmed by stripping the blots and reprobing with lamin (Sigma). The immunoblots shown here for lean and obese subjects are representative of five independent experiments with similar results. (b-c) For activity assay of HDAC and NF-кBp65, $10 \mu \mathrm{g}$ nuclear lysates were taken for determination of HDAC and NF-kBp65 activity. The experiment was done according to the manufacturer's instructions. Absorbance was taken at $405 \mathrm{~nm}$ and $450 \mathrm{~nm}$, respectively, by using an ELISA reader. Results are mean values (for five independent experiments), with standard deviations represented by vertical bars. * Mean value was significantly different from that of the untreated Tregs $(P<0.05)$. (d) EGCG treatment induced HDAC-2 activation in Tregs by immunofluorescence. The cells $\left(50-60 \%\right.$ confluent) were treated with and without $20 \mu \mathrm{M}-\mathrm{EGCG}$ for $24 \mathrm{~h}$. Cells were fixed with $4 \%$ formaldehyde for $30 \mathrm{~min}$ at $4{ }^{\circ} \mathrm{C}$ and stained overnight at $4{ }^{\circ} \mathrm{C}$ with HDAC-2 and -3 antibodies as described in Experimental methods. Data from a typical experiment of five are shown; magnification $\times 400$. DAPI, 4',6-diamidino-2-phenylindole; $\rightarrow$ increased intracellular expression. 
Effect of epigallocatechin gallate on activation of $N F-\kappa B$ and histone deacetylase levels in regulatory $T$ cells

Next, we studied specific regulation mechanisms. Acetylation of histone protein is associated with increased binding of the transcription factor NF- $\kappa B^{(12)}$. We studied the effects of EGCG on deacetylation of histone proteins, HDAC activity, transactivation and translocation of NF- $\mathrm{KB}$ in Tregs of both subject groups. Using immunoblot analysis, we observed that EGCG treatment $(20 \mu \mathrm{M})$ of cells resulted in decreased NF- $\mathrm{\kappa Bp} 65$ in the nuclear fraction in Tregs of the obese and lean subject groups (Fig. 3(a)). We further confirmed the inhibition of NF-kBp65 transactivation (lean: untreated 0.446 (SD 0.019), EGCG treated 0.329 (SD 0.049) v. obese: untreated 0.54 (SD 0.02 ), EGCG treated $0.3(\mathrm{SD} 0.05)$ at $450 \mathrm{~nm}$ optical density value) by performing ELISA (Fig. 3(c)). Also, EGCG enhanced total HDAC activity (lean: untreated 34.22 (sD 3.87) $\mu \mathrm{M}$, EGCG treated 51.78 (SD 2.31) $\mu \mathrm{M} v$. obese: untreated 22.1 (SD 2.1) $\mu \mathrm{M}$, EGCG treated 38.08 (SD 1.5) $\mu \mathrm{M}$ ) and HDAC-2 levels in the Tregs of obese and lean subject groups (Fig. 3(b) and (d) - immunofluorescence). There was no detectable significant difference for the HDAC- 3 in the Tregs of lean subjects (Fig. 3(d)). But EGCG increased HDAC-3 levels in the Tregs of obese subjects (Fig. 3(d)). Thus, EGCG appears to enhance IL-10 production and Treg number through, at least in part, suppressing the NF- $\mathrm{\kappa B}$ signalling pathway via inducing HDAC activity in the Tregs of both groups.

\section{Discussion}

Obesity predisposes to increased diabetes and atherosclerosis and related complications, which represent the major cause of morbidity and mortality in the Western world. Obese individuals exhibit impaired immune responses. Immune and autoimmune responses are controlled by a fine balance between effector T cells (Teffs) and Tregs ${ }^{(3)}$. Tregs constitutively express high levels of the IL-2 receptor $\alpha$ chain (CD25) and specifically express the forkhead/winged helix transcription factor Foxp3 which acts in a regulatory capacity by inhibiting the activation and function of both self-antigenand foreign-antigen-reactive $\mathrm{T}$ cells ${ }^{(18,19)}$. Moreover, Foxp3 plays a critical role for the development and function of Tregs $^{(8-10)}$. The critical physiological role of $\mathrm{CD} 4^{+} \mathrm{CD} 25^{+-}$ Foxp3 Tregs is to control autoimmune diseases ${ }^{(20,21)}$. Tregs may suppress by a contact-dependent mechanism or through the secretion of anti-inflammatory cytokines IL-10 and transforming growth factor- $\beta^{(1)}$. These cells are a low-frequency subpopulation of $\mathrm{CD}^{+}$cells, representing 1 to $2 \%$ of total lymphocytes. We hypothesised that enhancement of $\mathrm{CD} 4{ }^{+} \mathrm{CD} 25^{+}$Treg cell activity may protect individuals from impaired immune responses in patients with obesity.

Since ancient times, green tea has been considered a healthpromoting beverage. Health-promoting effects of green tea are mainly attributed to its polyphenol content. Green tea is a rich source of polyphenols, especially flavanols and flavonols. Catechins are the predominant flavanols and are mainly comprised of EGCG, epigallocatechin, epicatechin gallate and epicatechin $^{(15,22)}$. Several intervention studies have demonstrated that green tea cathechins containing $200-300 \mathrm{mg}$ EGCG exert beneficial effects on cardiovascular and metabolic health. Also, EGCG supplementation has been shown to be anti-inflammatory as evidenced by decreased cytokine release and NF- $\mathrm{KB}$ activity ${ }^{(23-26)}$. However, there are no data examining the effect of EGCG on the number and function of Tregs in the obese.

In the present study, we provide important and novel preliminary data showing (1) decreased number and function of Tregs (decreased IL-10) in obese individuals in vivo compared with matched lean controls (Fig. 1) and (2) in vitro treatment with EGCG enhances the number of Foxp3-positive Tregs in obese and lean subjects (Fig. 2); this is associated with increased IL-10 release (Fig. 2), decreased NF-кB activity and up-regulation of HDAC-2 (Fig. 3) in support of the earlier observations ${ }^{(23-26)}$. NF- $\mathrm{KB}$ plays a pivotal role in inflammation, and EGCG has been shown to down-regulate NF- $\mathrm{\kappa B}$ in other studies; however, the effect of EGCG on Tregs has not been studied. Similar to other previous reports ${ }^{(23-26)}$, in the present study we show that EGCG promotes the number and function of Tregs (IL-10 release) in both lean and obese subjects in vitro. Furthermore, since Foxp3-expressing Tregs are more effective in affecting the functionality of Tregs, we examined the effect of EGCG treatment in vitro on Foxp $3^{+}$Tregs and similar findings were observed, i.e. enhancement of Foxp $3^{+}$ Tregs and IL-10 release in both lean and obese subjects.

Epigenetics refers to heritable changes in phenotype (appearance) or gene expression caused by mechanisms other than changes in the underlying DNA sequence. Histone acetylation-deacetylation is an important epigenetic event that plays an important role in inflammation ${ }^{(11)}$. Acetylation of histone protein is associated with increased binding of the transcription factor NF- $\mathrm{KB}^{(12)}$. While several other nutritional strategies such as curcumin and resveratrol have been shown to promote epigenetic events resulting in decreased inflammation, the effect of EGCG on chromatin remodelling has not been studied. Furthermore, in monocytes, inflammation and NF-кB appear to be regulated by changes in histone acetylationdeacetylation. Thus, we tested if EGCG up-regulates the number and anti-inflammatory activity of Tregs (by suppressing NF-кB) through chromatin remodelling. Here, we show that EGCG alters HDAC activity and severely suppresses NF-кB, leading to increased IL-10 release in both obese and lean subjects.

In conclusion, EGCG up-regulates the number and antiinflammatory activity of Tregs through chromatin remodelling by alteration of histone acetylation-deacetylation and suppression of NF- $\mathrm{KB}$, leading to the induction of IL-10 release. However, the molecular mechanism of chromatin remodelling for pro-inflammatory genes in Tregs is not yet understood well and will be the focus of future studies. Furthermore, it will be important to confirm these in vitro findings in a placebo-controlled supplementation study of EGCG in obese human volunteers. Understanding of gene expression and epigenetic modulation of Tregs by EGCG may be, at least in part, a promising strategy to modulate the immune response of the complications of obesity and its associated diseases and future studies will examine the effect of EGCG supplementation in obese human subjects.

\section{Acknowledgements}

These studies were supported in part from discretionary research funding available to the corresponding author S. D. and through a mentoring award to the co-investigator 
I. J. (NIH K24 AT 00596). J.-M. Y. performed the research procedures and wrote the manuscript. S. D. supervised all parts of the project, and assisted with obtaining informed consent from subjects and manuscript preparation. I. J. provided assistance with the discussion.

The authors acknowledge the help of Manpreet Kaur for editorial assistance.

No conflicts of interest are reported from any of the authors.

Supplemental Fig. 1 is available online only at http:// journals.cambridge.org/action/displayJournal?jid = bjn

\section{References}

1. Yusuf S, Hawken S, Ounpuu S, et al. (2004) INTERHEART Study Investigators: effect of potentially modifiable risk factors associated with myocardial infarction in 52 countries (the INTERHEART study): case-control study. Lancet 364, 937-952.

2. Visser M, Bouter LM, McQuillan GM, et al. (1999) Elevated C-reactive protein levels in overweight and obese adults. JAMA 282, 2131-2135.

3. O'Garra A \& Vieira P (2004) Regulatory T cells and mechanisms of immune system control. Nat Med 10, 801-805.

4. Sakaguchi S (2005) Naturally arising Foxp3-expressing $\mathrm{CD} 25^{+} \mathrm{CD} 4^{+}$regulatory $\mathrm{T}$ cells in immunological tolerance to self and non-self. Nat Immunol 6, 345-352.

5. Brusko TM, Wasserfall CH, Clare-Salzler MJ, et al. (2005) Functional defects and the influence of age on the frequency of $\mathrm{CD} 4{ }^{+} \mathrm{CD} 25^{+} \mathrm{T}$ cells in type 1 diabetes. Diabetes 54, 1407-1414.

6. Lindley S, Dayan CM, Bishop A, et al. (2005) Defective suppressor function in $\mathrm{CD} 4{ }^{+} \mathrm{CD} 25^{+} \mathrm{T}$-cells from patients with type 1 diabetes. Diabetes 54, 92-99.

7. Meier P, Meier R \& Blanc E (2008) Influence of $\mathrm{CD} 4^{+} / \mathrm{CD} 25^{+}$ regulatory $\mathrm{T}$ cells on atherosclerosis in patients with end-stage kidney disease. Expert Rev Cadiovasc Ther 6, 987-997.

8. Gambineri E, Torgerson TR \& Ochs HD (2003) Immune dysregulation, polyendocrinopathy, enteropathy, and X-linked inheritance (IPEX), a syndrome of systemic autoimmunity caused by mutations of FOXP3, a critical regulator of T-cell homeostasis. Curr Opin Rheumatol 15, 430-435.

9. Bennett CL, Christie J, Ramsdell F, et al. (2001) The immune dysregulation, polyendocrinopathy, enteropathy, X-linked syndrome (IPEX) is caused by mutations of FOXP3. Nat Genet 27, 20-21.

10. Brunkow ME, Jeffery EW, Hjerrild KA, et al. (2001) Disruption of a new forkhead/winged-helix protein, scurfin, results in the fatal lymphopoliferative disorder of the scrufy mouse. Nat Genet 27, 68-73.

11. Rahman I, Marwick J \& Kirkham P (2004) Redox modulation of chromatin remodeling: impact on histone acetylation and deacetylation, NF- $\mathrm{kB}$ and pro-inflammatory gene expression. Biochem Pharmacol 15, 1255-1267.

12. Rahman I, Gilmour PS, Jimenez LA, et al. (2002) Oxidative stress and TNF- $\alpha$ induce histone acetylation and NF- $\mathrm{KB} / \mathrm{AP}-1$ activation in alveolar epithelial cells: potential mechanism in gene transcription in lung inflammation. Mol Cell Biochem 234, 239-248.

13. Ito K, Barnes PJ \& Adcock IM (2000) Glucocorticoid receptor recruitment of histone deacetylase 2 inhibits interleukin$1 \beta$-induced histone $\mathrm{H} 4$ acetylation on lysines 8 and 12 . Mol Cell Biol 20, 6891-6903.

14. Ashburner BP, Westerheide SD \& Baldwin AS Jr (2001) The p65 (RelA) subunit of NF-кB interacts with the histone deacetylase (HDAC) corepressors HDAC1 and HDAC2 to negatively regulate gene expression. Mol Cell Biol 21, 7065-7077.

15. Wolfram S (2007) Effects of green tea and EGCG on cardiovascular and metabolic health. J Am Coll Nutr 26, 373S-388S.

16. Rahman I, Biswas SK \& Kirkham PA (2006) Regulation of inflammation and redox signaling by dietary polyphenols. Biochem Pharmacol 30, 1439-1452.

17. Sun Y, Li H, Langnas AN, et al. (2004) Altered allogeneic immune responses in middle-aged mice. Cell Mol Immunol 1, $440-446$

18. Levings MK, Sangregorio R \& Roncarolo MG (2001) Human $\mathrm{CD} 25^{+} \mathrm{CD} 4^{+} \mathrm{T}$ regulatory cells suppress naive and memory $\mathrm{T}$ cell proliferation and can be expanded in vitro without loss of function. J Exp Med 193, 1295-1302.

19. Shevach EM (2001) Certified professionals: $\mathrm{CD} 4{ }^{+} \mathrm{CD} 25^{+}$ suppressor T cells. J Exp Med 193, F41-F46.

20. Jonuleit H, Schmitt E, Schuler G, et al. (2000) Induction of interleukin 10-producing, nonproliferating $\mathrm{CD} 4^{+} \mathrm{T}$ cells with regulatory properties by repetitive stimulation with allogeneic immature human dendritic cells. J Exp Med 192, 1213-1222.

21. Read S \& Powrie F (2001) CD4 ${ }^{+}$regulatory T cells. Curr Opin Immunol 13, 644-649.

22. Yang CS \& Landau JM (2000) Effects of tea consumption on nutrition and health. J Nutr 130, 2409-2412.

23. Calixto JB, Campos MM, Otuki MF, et al. (2004) Antiinflammatory compounds of plant origin. Part II. Modulation of pro-inflammatory cytokines, chemokines and adhesion molecules. Planta Med 70, 93-103.

24. Kim SJ, Jeong HJ, Lee KM, et al. (2007) Epigallocatechin3-gallate suppresses NF- $\mathrm{B}$ activation and phosphorylation of p38 MAPK and JNK in human astrocytoma U373MG cells. J Nutr Biochem 18, 587-596.

25. Basu A \& Lucas EA (2007) Mechanisms and effects of green tea on cardiovascular health. Nutr Rev 65, 361-375.

26. Hong MH, Kim MH, Chang HJ, et al. (2007) (-)-Epigallocatechin-3-gallate inhibits monocyte chemotactic protein-1 expression in endothelial cells via blocking NF-кB signaling. Life Sci 1, 1957-1965. 